\title{
Phenotypic Variation Among Four Family Members with Congenital Hypothyroidism Caused by Two Distinct Thyroglobulin Gene Mutations
}

\author{
Viviane Pardo, ${ }^{1}$ Ileana G.S. Rubio, ${ }^{1}$ Meyer Knobel, ${ }^{1}$ Manoel H. Aguiar-Oliveira, ${ }^{2}$ Marcos M. Santos, ${ }^{2}$ \\ Simone A. Gomes, ${ }^{2}$ Carla R.P. Oliveira, ${ }^{2}$ Hector M. Targovnik, ${ }^{3}$ and Geraldo Medeiros-Neto ${ }^{1}$
}

Background: Thyroglobulin ( $\mathrm{Tg}$ ) is a large glycoprotein that is intimately involved in the biosynthesis of thyroxine and triiodothyronine. At least 38 mutations have been described in the Tg gene that are associated with varying degrees of hypothyroidism. We studied the Tg gene in four related subjects with congenital hypothyroidism. Summary: We found a novel compound heterozygous constellation (IVS30 + 1G > T/A2215D) in a brother and sister and one previously described related mutation (IVS30+1G $>$ T) in their two sibling second degree cousins. The brother with the IVS30 + 1G > T/A2215D mutation and the two siblings with the IVS30+1G $>$ T mutation had fetal or neonatal goiter and all had hypothyroidism.

Conclusions: This study further confirms the association of the IVS30+G $>$ T mutation of the Tg gene with hypothyroidism. Computer analysis predicts that the A2215D mutation, first reported here, should cause structural instability of Tg but when present as a compound heterozygous mutation with IVS30+G $>$ T/A its effect is unclear but is likely to be influenced by iodine intake.

\section{Introduction}

$\mathbf{T}$ HyRoglobulin (Tg) IS a LARge GLyCoprotein and functions as a matrix for thyroid hormone synthesis. The coding gene is located on chromosome 8q24 and contains an $8.5-\mathrm{kb}$ coding sequence divided into 48 exons (1). Thirtyeight inactivating mutations have been identified in the human $\mathrm{Tg}$ gene and at least 12 alternative splice products have been detected in wild-type Tg mRNA (2). We herein describe four children with congenital hypothyroidism $(\mathrm{CH})$ due to Tg defective synthesis in an inbred family from northeastern Brazil and a new $\mathrm{Tg}$ compound heterozygous constellation.

Patient IV-2 and IV-3. The two affected siblings from this kindred were born to non-consanguineous parents (Fig. 1). Patient IV-3 had with neonatal goiter by history. At the age of 11.7 years, he presented with stunted growth (height age of 7 years), delayed bone age (9 years), and thyroid enlargement $(21.3 \mathrm{~mL})$ by ultrasound (US). He was started on L-thyroxine $5 \mu \mathrm{g} / \mathrm{kg}$ and 3 months later serum thyroxine $\left(\mathrm{T}_{4}\right)$ and triiodothyronine $\left(\mathrm{T}_{3}\right)$ were normal but recombinant human thyrotropin (rhTSH)-stimulated Tg was low (Table 1). L-thyroxine treatment was continued and the patient had normal somatic development but mild mental retardation $(I Q=65)$. Patient IV-2, the second-born daughter had thyroid enlargement, elevated serum TSH, and normal serum $\mathrm{T}_{3}$ and $\mathrm{T}_{4}$ at 2 months (Table 1). She was started on L-thyroxine $10 \mu \mathrm{g} / \mathrm{kg}$ per day and at age of 11 years, she had normal thyroid volume, normal thyroid function tests, unremarkable somatic development, and no mental retardation $(I Q=96)$.

Patients $V-1$ and $V$-2. They are second-degree cousins of the first two patients and were born to consanguineous parents (3) (Fig. 1). Patient V-1 was the first-born son. By history he had a neonatal goiter and was started on L-thyroxine during his first year of life with visible reduction in goiter. At age 6 while on L-thyroxine, $\mathrm{TSH}, \mathrm{T}_{3}$, and $\mathrm{T}_{4}$ were normal but rhTSH stimulated Tg was low (Table 1). Bone age was delayed (32 months) and he had mental retardation $(\mathrm{IQ}=63)$. The history of patient $\mathrm{V}-2$ revealed that US of her mother at 26 weeks of gestation identified a large fetal goiter (volume $12.3 \mathrm{~mL}$ ). At 29 weeks, fetal hypothyroidism was confirmed by cordocentesis (TSH $61.3 \mathrm{mU} / \mathrm{L}$ ) (Table 1). Four weeks after a single intra-amniotic injection of L-thyroxine

\footnotetext{
${ }^{1}$ Thyroid Study Unit (LIM-25), Division of Endocrinology, University of São Paulo Medical School, São Paulo, Brazil.

${ }^{2}$ Division of Endocrinology, Federal University of Sergipe Medical School, Aracajú, Brazil.

${ }^{3}$ Facultad de Farmacia y Bioquímica, Universidad de Buenos Aires, Buenos Aires, Argentina.
} 


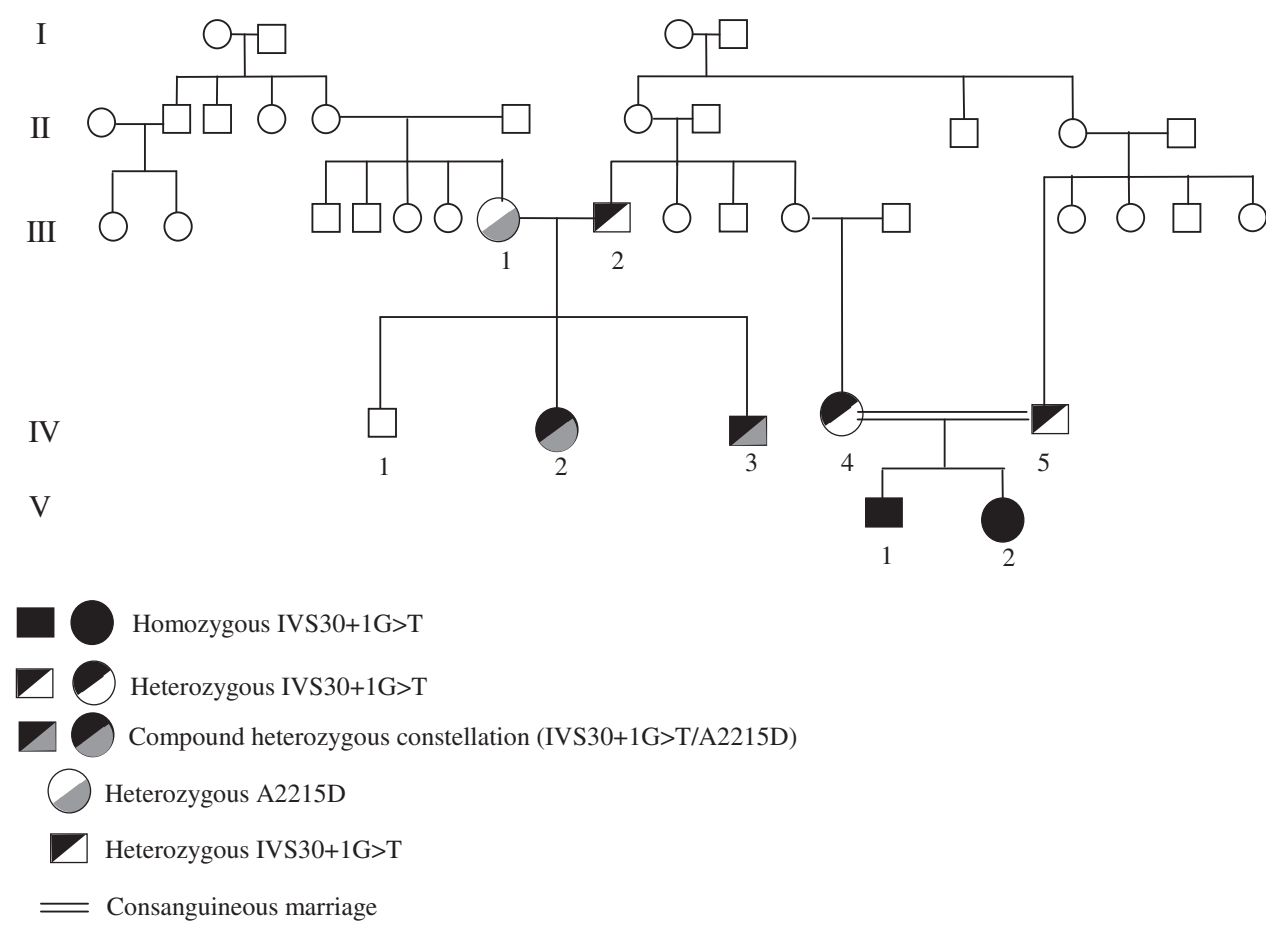

FIG. 1. Family pedigree. Siblings V-1 and V-2 had the homozygous mutation IVS $30+1 \mathrm{G}>\mathrm{T}$ and patients IV-2 and IV-3 had the compound heterozygous constellation IVS30 $+1 \mathrm{G}>\mathrm{T} / \mathrm{A} 2215 \mathrm{D}$. Note: Genomic DNA was isolated from peripheral blood DNA by the sodium dodecyl sulfate-proteinase $\mathrm{K}$ method. The complete coding sequence of the Tg gene, including splicing signals and flanking intronic regions of each intron, was amplified by polymerase chain reaction (PCR) (13). DNA sequencing from each amplified fragment was performed with DYEnamic ET dye Terminator kit (Megabace, Amersham Biosciences, GE, Piscataway, NJ). The sequences were compared with the human Tg gene sequence (GenBank accession number NY_008046).

$400 \mu \mathrm{g}$, marked reduction in the goiter was noted on US $(4.8 \mathrm{~mL})$. Cord serum $\mathrm{TSH}$, total $\mathrm{T}_{4}$, and free $\mathrm{T}_{4}$ were normal at birth, thyroid volume was $1.8 \mathrm{~mL}$, and serum $\mathrm{Tg}$ level was at the lower limit of detection (Table 1). At 5 years somatic and mental development were normal $(\mathrm{IQ}=96)$.

In all patients, absence of synthesis and secretion of $\mathrm{Tg}$ was confirmed by lack of serum Tg elevation 24 and 48 hours after $0.1 \mathrm{mg}$ intramuscular injection of rhTSH (Table 1) (4). At the time of this study all the patients had excessive iodine intake (urinary iodine concentration 335-492 $\mathrm{g} / \mathrm{L}$, normal range $100-299 \mu \mathrm{g} / \mathrm{L})$ (5). In siblings $\mathrm{V}-1$ and V-2 direct se- quencing revealed the homozygous mutation IVS30+1G $>\mathrm{T}$ $(6,7)$. Their parents were heterozygous for this mutation (Fig. 1).

In patients IV-2 and IV-3, we identified a novel compound heterozygous constellation IVS30+1G $>$ T/A2215D. The heterozygous A2215D mutation (8) was also found in these patients' mother, and the heterozygous IVS30+1G $>\mathrm{T}$ in the patients' father (Fig. 1).

This intronic mutation is caused by guanine to thymine transversion at position +1 in the donor splice site of intron 30 , promoting an aberrant splicing and loss of the entire exon 30 (138 nt) in the resulting mRNA $(6,7)$. Elimination of this

Table 1. Laboratory Data of the Patients ${ }^{a}$

\begin{tabular}{|c|c|c|c|c|c|c|}
\hline \multirow[b]{2}{*}{ Patients } & \multirow{2}{*}{$\begin{array}{l}\text { TSH } \\
(m U / L)\end{array}$} & \multirow{2}{*}{$\begin{array}{l}\text { Total } T_{3} \\
(\mathrm{nmol} / \mathrm{L})\end{array}$} & \multirow{2}{*}{$\begin{array}{l}\text { Total } T_{4} \\
(\mathrm{nmol} / \mathrm{L})\end{array}$} & \multirow{2}{*}{$\begin{array}{l}\text { Free } T_{4} \\
(\mathrm{pmol} / \mathrm{L})\end{array}$} & \multicolumn{2}{|c|}{$\operatorname{Tg}(\mu g / L)$} \\
\hline & & & & & Basal & Stimulated rhTSH \\
\hline IV-2 & 23 & 3.1 & 61.8 & - & 0.7 & 0.6 \\
\hline IV $-3^{b}$ & 0.83 & 3.2 & 121 & - & 0.8 & 0.5 \\
\hline $\mathrm{V}-1^{\mathrm{b}}$ & 0.9 & 2.8 & 154.4 & 24.5 & $<0.1$ & $<0.1$ \\
\hline$V-2^{c}$ & 61.3 & 0.5 & 38.6 & 2.6 & 1.3 & - \\
\hline$V-2^{d}$ & 41.6 & 2.0 & 135 & 11.5 & $<0.1$ & $<0.1$ \\
\hline Reference & $0.5-4.0$ & $1.2-3.1$ & 51-155 & $11-25$ & $0.5-15.0$ & $\underline{e}^{\mathrm{e}}$ \\
\hline
\end{tabular}

${ }^{\mathrm{a}} \mathrm{TSH}$, thyrotropin; $\mathrm{T}_{3}$, triiodothyronine; $\mathrm{T}_{4}$, thyroxine; $\mathrm{Tg}$, thyroglobulin; rhTSH, recombinant human thyrotropin.

${ }^{\mathrm{b}}$ During treatment with L-thyroxine.

'Cordocentesis at 29 weeks' gestation.

${ }^{\mathrm{d}}$ Cordocentesis at birth (cord blood).

'Stimulation with rhTSH increases serum Tg levels 4-6 fold from baseline levels. 
exon does not affect the reading frame of the mRNA and potentially codifies a shortened polypeptide. The deletion is localized in the Tg type III repeat domain, causing the loss of 1- putative N-linked glycosylation site (2). The loss of 46 amino acids can modify the tertiary/quaternary structure of the protein which is then retained inside the endoplasmic reticulum (ER), reducing the export of the protein to the colloid (9). This mechanism is known as the quality control of the ER, and is mediated by molecular chaperones (9). In patient V-2, fetal goiter and severe fetal hypothyroidism (Table 1) are clearly the consequence of biosynthetic defects in fetal thyroid hormonogenesis. Other causes of fetal goiter, such as deficiency or excess of iodine, exposure to goitrogens, ingestion of medications that affect the fetal thyroid gland, and maternal thyroid autoimmune disease were excluded in this patient (10). Consequently, the IVS30+1G $>\mathrm{TTg}$ mutation is certainly the main etiological factor for the clinical findings of the patient. In the eldest sibling (V-1) this mutation also led to a severe clinical condition with stunted growth and mental retardation despite L-thyroxine replacement during the first year of life. The early intra-utero and uninterrupted L-thyroxine therapy after birth of his sister allowed a normal somatic development and absence of neurological sequelae.

The mutation A2215D is caused by cytosine to adenine nucleotide transition at position 6701 in exon $38(6701 \mathrm{C}>\mathrm{A})$. This alteration changed alanine to aspartic acid in position 2215 of the protein (A2215D) localized in the AChE homology domain of the $\mathrm{Tg}(8)$. Alignment analysis revealed that the wild-type alanine residue at position 2215 is strictly conserved in all $\mathrm{Tg}$ and $\mathrm{AChE}$ species analyzed (8). Computer analysis showed that the A2215D mutation can cause the following changes on the protein structure: a) reduced stretch of the helix structure, b) reduced stretch of the $\beta$-sheet structure, c) extension of the helix, d) extension of the $\beta$-sheet, and e) introduction of a $\beta$-sheet (Protein Structure Predictionhttp://bioinf.cs.ucl.ac.uk/psipred). Consequently, this mutation may cause structural instability, impairing Tg export to the colloid. Park and Arvan (11) showed in an animal model that the AChE-like region of $\mathrm{Tg}$ functions as a dimerization domain, facilitating efficient intracellular transport of the much larger $\mathrm{Tg}$, via a secretory pathway. Congenital hypothyroidism in $\operatorname{cog} / \operatorname{cog}$ mice and $r d w$ rats is caused by a missense mutation in the AChE-like domain of the Tg molecule. Both mutated $\mathrm{Tg}$ proteins exhibit a severe defect in the exit from the ER, causing a thyroidal ER storage disease (12).

Patients IV-2 and IV-3 had CH secondary to the compound heterozygous Tg mutation (IVS30+1G $>$ T/A2215D). Elevated nutritional iodine intake may partially induce synthesis of thyroid hormones in the mutant Tg protein (1). Urinary iodine excretion in the affected patients was elevated, and the local population is exposed to a relatively high nutritional iodine environment through iodized salt and daily use of fish and seafood. Our hypothesis is that these patients probably synthesize low amounts of thyroid hormone within the frame of a mutant $\mathrm{A} 2215 \mathrm{D} \mathrm{Tg}$, enough for the requirement during the first months of postnatal life. This was clearly observed in the second-born girl (IV-2) who developed normally and had normal thyroid hormone levels at the age of 2 months. She was then treated with L-thyroxine and had normal IQ. Her brother, however, with the same Tg gene mutations and living in similar environmental conditions, had a less successful development and presented with some degree of mental retardation due to the delay in $\mathrm{CH}$ diagnosis.

In conclusion, we identified a novel compound heterozygous constellation (IVS30+1G $>$ T/A2215D) in two siblings and one previously described mutation (IVS30 $+1 \mathrm{G}>\mathrm{T}$ ) in two other siblings that caused defective $\mathrm{Tg}$ synthesis and consequent severe $\mathrm{CH}$. The mutation IVS30+1G $>\mathrm{T}$, that leads to an impaired $\mathrm{Tg}$ synthesis, affects the thyroid gland in utero, causing a large fetal goiter. The degree of mutant (A2215D) Tg that is able to escape the quality control of the cell along with constant high iodine nutrition will eventually determine the final phenotypic appearance.

\section{Acknowledgments}

We gratefully acknowledge the collaboration of biologist Maria Silvia Cardia for clinical laboratory work. We also acknowledge the help of Ana Luiza Galrão for the urinary iodine concentration analysis. This study had the financial support of FAPESP (grant 03/02989-8) and Instituto da Tiróide, São Paulo, Brazil, and was approved by the Ethical Committee of the Hospital das Clínicas, University of São Paulo Medical School. Informed consent was obtained from the parents of the patients.

\section{References}

1. Vono-Toniolo J, Rivolta CM, Targovnik HM, Medeiros-Neto G, Kopp P 2005 Naturally occurring mutations in the thyroglobulin gene. Thyroid 15:1021-1033.

2. Rivolta CM, Targovnik HM 2006. Molecular advances in thyroglobulin disorders. Clin Chim Acta 347:8-24.

3. Medeiros-Neto G, Bunduki V, Tomimori E, Gomes S, Knobel M, Martin RT, Zugaib M 1997. Clinical case seminar: prenatal diagnosis and treatment of dyshormonogenetic fetal goiter due to defective thyroglobulin synthesis. cri Metab 82:4239-4242.

4. Fugazzola L, Persani L, Mannavola D, Reschini E, Vannucchi G, Weber G, Beck-Peccoz P 2003 Recombinant human TSH testing is valuable tool for differential diagnosis of congenital hypothyroidism during L-thyroxine replacement. Clin Endocrinol 59:230-236.

5. Pino S, Fang SL, Braverman LE 1996 Ammonium persulfate: a safe alternative oxidizing reagent for measuring urinary iodine. Clin Chem 42:239-243.

6. Targovnik H, Vono J, Billerbeck AEC, Cerrone GE, Varela V, Mendive F, Wajchenberg BL, Medeiros-Neto G 1995 A 138nucleotide deletion in the thyroglobulin ribonucleic acid messenger in a congenital goiter with defective thyroglobulin synthesis. I Clin Endocrinol Metab 80:3356-3360.

7. Targovnik HM, Rivolta CM, Mendive FM, Moya CM, Medeiros-Neto G 2001 Congenital goiter with hypothyroidism caused by a $5^{\prime}$ splice site mutation in the thyroglobulin gene. Thyroid 11:685-690.

8. Caputo M, Rivolta CM, Esperante SA, Gruñeiro-Papendieck L, Chiesa A, Pellizas CG, González-Sarmiento R, Targovnik H 2007 Congenital hypothyroidism with goitre caused by new mutations in the thyroglobulin gene. Clin Endocrinol 67:351-357.

9. Medeiros-Neto G, Kim PS, Yoo SE, Vono J, Targovnik HM, Camargo R, Hossain A, Arvan P 1996 Congenital hypothyroid goiter with deficient thyroglobulin. Identification of an endoplasmic reticulum storage disease with induction of molecular chaperones. J Clin Invest 98:2838-2844. 
10. Ghazi AM, Ordookhani A, Pourafkari M, Fallahian M, Bahar A, Hedayati M, Hafizi A, Azizi F 2005 Intrauterine diagnosis and management of fetal goitrous hypothyroidism: a report of an Iranian family with three consecutive pregnancies complicated by fetal goiter. Thyroid 15:1341-1347.

11. Park YN, Arvan P 2004. The acetylcholinesterase homology region is essential for normal conformational maturation and secretion of thyroglobulin. J Biol Chem 279:17085-17089.

12. Kim PS, Hossain SA, Park Y-N, Lee I, Yoo S-E, Arvan P 1998 A single amino acid change in the acetylcholinesterase-like domain of thyroglobulin causes congenital goiter with hypothyroidism in the $\operatorname{cog} / \operatorname{cog}$ mouse: a model of human endoplasmic reticulum storage diseases. Proc Natl Acad Sci U S A 95:9909-9913.

13. Gutnisky VJ, Moya CM, Rivolta CM, Domené S, Varela V, Toniolo JV, Medeiros-Neto G, Targovnik HM 2004 Two distinct compound heterozygous constellation (R277X/ IVS34-1GNC and R277X/R1511X) in the thyroglobulin (Tg) gene in affected individuals of a Brazilian kindred with congenital goiter and defective Tg synthesis. J Clin Endocrinol Metab 89:646-657.

Address reprint requests to: Geraldo Medeiros-Neto Thyroid Unit (LIM 25) University of São Paulo Medical School Av. Dr. Arnaldo, 455, sala 4309-C. CEP: 01246-903 São Paulo, SP Brazil

E-mail: medneto@uol.com.br 